\title{
Blending Wattpad Platform and English Prose Course in Industrial Revolution Era 4.0
}

\author{
Irpan Ali Rahman'1), Iwan2) \\ 1), 2) Universitas Buddhi Dharma, Tangerang, Banten, Indonesia \\ 1)Irpanalirahman@gmail.com, ${ }^{2)}$ iwanhatanto@yahoo.com
}

\begin{abstract}
This paper focuses on an exploration of Wattpad platforms and English prose course as blended learning models in undergraduate students. In the era of industrial revolution 4.0 , the use of blended learning models is an alternative solution to the challenges of the times in integrating technological progress with learning. This study used descriptive qualitative research method to examine the concept of blending of wattpad platforms and English prose course. This research finding showed that wattpad platforms as a digital media resources contain intellectual property in the form of prose literary works with various genres. It is very interesting to be used as English teaching material. Wattpad offers easy access to English prose material so that it is more flexible to maximize the time and place of the English learning process. English prose that contains language content such as vocabulary, phrases, sentences, and dialogues which become the media of the writer to express his ideas to his readers. The use of wattpad platforms media helps students as literary readers in transferring the contents of literary works to their readers to obtain a more meaningful learning process because it is rich in moral and social values. In addition, wattpad platforms offer opportunities to respond and appreciate literary work through the reader response features provided by wattpad. Through blended learning design, English learning process can be done either face-toface or online between lecturers and students to provide maximum learning outcomes. In the end, the learning design of the blending wattpad platforms with the English prose course is expected to be implemented as an alternative in learning English processes for advanced learners.
\end{abstract}

Keywords: blended learning, wattpad platform, English prose course

Citation APA Style: Rahman, I. A., \& Iwan. (2019). Blending Wattpad Platform and English Prose Course in Industrial Revolution Era 4.0. English Language in Focus (ELIF), 2(1), 25-32.

\section{INTRODUCTION}

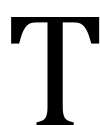

he industrial revolution 4.0 is marked by the rampant progress of artificial intelligence, machine learning, biotechnology, internet of things, and driverless vehicles. The industrial revolution 4.0 has fundamentally changed human life. The advancement of new technology on a wider and more complex scale results in the integration of the physical world with digital which affects all disciplines. One 
of the disciplines affected by the pace of the industrial revolution 4.0 is the realm of education. Education 4.0 is a term used by education experts to describe various efforts to integrate cyber technology into the world of learning. The positive response is shown by the educational world by integrating cyber technology and learning to respond to the needs of the industrial revolution to be able to prepare a competitive and productive millennial generation.

Blended learning is an effort to integrate cyber technology and learning today. Jeffrey, Milne, Suddaby, \& Higgins (2014) stated that the use of technology has increased the breadth and depth to access the educational world. The technology-based learning model or blended learning aims to combine learning face to face and virtually. The use of blended learning not only integrates learning models, learning styles but also learning media. The benefits of using blended learning in education are creating time and place flexibility to access learning material.

The Wattpad platform is one of the digital technology media that can be collaborated with learning. The Wattpad platform features digital stories with various literary genres such as fanfiction, teen-fiction, romance, action and other genres without having innate heavy books to enjoy the story. The student can simply open the Wattpad platform to access it anytime and anywhere. Wattpad platform can help students to develop not only reading skills but also writing, grammar, vocabulary and speaking skills which make them excellent materials in the EFL courses. The Wattpad platform contains various stories which can apply to undergraduate students in the English Letters Department. They learn to read and write the stories as authentic learning material in the English Prose course. The English prose is one of the major discussions in the English Letters Department. The English language course provides a means for learning a language with comprehension. English prose is also authentic learning material containing stories with meaningful experiences through the plot, characters, and settings. Understanding the stories in the process will stimulate the students to appreciate the literary works and reflect the moral values then finally they can share their own stories in simple process writing.

English prose is as a genre in literature providing complex language use and extraordinary context which will give a unique challenge for students to understand the whole meaning. It needs much more and flexible time and place to access the English prose to have meaningful learning objectives. Moreover, the process is usually printed books and special needs space to bring and need spare time to enjoy reading. Blending wattpad apps and English prose courses become an alternative learning method to reduce the obstacles to give students' more flexible time and place to learn the English prose.

\section{RESEARCH METHODOLOGY}

$\mathrm{n}$ this study, the writer uses
descriptive qualitative research
because this research focuses on analyzing constructive thought ideas. Qualitative research is more holistic and often involves a rich collection of data 
from various sources to gain a deeper understanding of individual participants, including their opinions, perspectives, and attitudes. This often involves an inductive exploration of the data to identify recurring themes, patterns, or concepts and then describing and interpreting those categories (Nassaji, 2015). Qualitative descriptive method is a method of researching, an object, a set of conditions, a system of thought to make a description, a systematic, factual and accurate description of the facts, properties, and relationships between the phenomena investigated. Thus, the exploration of data in the form of opinions and perspectives that build a concept of thought.

\section{FINDING AND DISCUSSION}

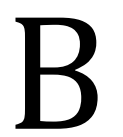

\section{lended Learning Model}

Morris in Alkhaleel (2019) stated that blended learning became prospective learning model for higher education students. This model covered the improvement of face-to-face interface between teachers and learners in the internet or computer bases. Blended learning is an important part of the activities in two different areas; person and online. The blended framework can cover a significant part in pedagogies, problem-based learning, cooperative learning, and others. The challenge that forms blended learning is to connect what occurs between face-to-face and online activities strengthen each other to create a single and united course. In addition, Jeffrey et al (2014) stated that blended learning has been described as a model of teaching that eliminates time, place, and situation while enabling highquality interactions between teachers and students. There are three major categories of the student to measure blended learning practices as follow 1). Getting Students Engaged: Capturing student attention at the start of the course; 2). Maintaining Engagement: Maintaining student engagement through the course with clear instruction and guidance, authentic tasks and clear feedback; 3). Re-engaging Students: providing personal monitoring. In summary, the blended learning model offers very interesting learning model which combine face to face and online session to give attention, feedback and personal monitoring to the student.

\section{Wattpad Platform}

One of the platforms is relevant to the characteristic of blended learning namely wattpad platform which becomes the medium between face to face and online using digital platforms. Wattpad platform is an online community for writers. Bal (2018) explained wattpad was founded by Allen Lau and Ivan Yuen in 2006. It is an application developed for online reading and writing. Wattpad has more than 65 million users (Tirocchi, 2018). Wattpad provides many new possibilities for enriching reading and writing experiences. It features a wide range of genres, including action, general fiction, paranormal, mystery, spiritual, fantasy, humor, young chick-lit, romance, classics, science fiction, adventure, teenfiction, fanfiction, historical fiction, and nonfiction.

Wattpad platform is to establish the authenticity of well-known authors and several less well-known authors, who are traditionally published, that have not been verified. To give an 
overview of the most popular 150 authors such as Margaret Atwood, Paulo Coehlo, Dan Brown, R.L. Stine, and Marian Keyes. The genres offer popular literary genre such as Teen Fiction and Romance is as a genre that appeals to all ages readers. Other popular genres include Fan Fiction, Chick-lit and Urban Fiction. The use of genre classification in wattpad platform is interesting genre features in order the readers can choose the appropriate genres for their need (Bold, 2018).

\section{English Prose Course}

Prose is a unique written similar with the spoken language which consists of words, phrases, sentences, paragraphs, punctuation, grammar, and vocabulary to develop the author's message. Gill (1995, p. 105) explained that prose is a literary work that invites its readers to imagine in the narrative world. In the process of reading prose, students will be invited to find the message and moral values. The process of reading poetry will lead the students to better appreciate life and be more sensitive to the environment. Reading a story means you are reading a work of fiction. Fiction is writing that comes from a work of the author's imagination. Prose offers fiction and nonfiction genre. Prose is a literary work which tends to convey the author's point of view to entertain the readers. The prose authors produce a short story, novel, novella. English prose developed from the Middle Ages delighted in long romantic narrative poems, the Elizabethans period is known as drama period, the Victorian period is famous with novels until today in modern age prose. The main ideas of prose reflected every experience and knowledge in every civilization period.

The study of literature like English prose stimulates the students to the imagined worlds so they can explore, examine, and reflect the story issues to their real life. The critical thinking skills helps the students to understand the ideas in literary work such as questioning, exploring personal and social issues, and interrogating and managing various perspectives. Burke and Brumfit cited in Novianti (2016) explained the aims of teaching literature are to promote students' literary skills and social skills and to encourage them to sharpen their liberalism, ethnicity, and humanitarian attitudes as well as providing necessary information and knowledge. There are the procedure to select the appropriate English literature materials for EFL students as follow; 1). Selecting the appropriate texts of various literary genres; 2). Lecturer reviews the numbers of literary texts to select the appropriate students' task; 3). the lecturers select the length of the literary work that appropriates to students' needs. The levels of language difficulty, such as vocabulary and grammatical structure, other kinds of knowledge are taken as the consideration of the literary reading texts.

Ezeokoli (2016) stated that literature owns the potentials to challenge, stimulate and build the students' reading passion. The literary work builds students' self-confidence in their ability to understand the deep meaning from text and encourages students to explore their opinions. Literature offers a wide exploration and growth in the competencies required for 
modern times. Investigating of text through critical reading enhances students' analytical capability and challenges them to practice their critical thinking. Studying literature will train the students' empathy and selfconfidence to be active in participating and contributing to society.

\section{Blended Wattpad Application and English Prose in IR 4.0}

Applying blended learning by using technology 'wattpad platform' integrating to the knowledge in English prose is the proof of the positive perspective in the industrial revolution 4.0 to achieve better quality in literature and language courses in undergraduate students. Rovai and Jordan in Alkhaleel (2019) explained blended learning has some benefit in freedom and flexibility access. One of the learning technology to support blended learning is wattpad platform. Tirocchi (2018) explained that Wattpad is a very interesting digital environment with a huge amount of potential for schools and learning. Wattpad provides the opportunity to reflect on the value of reading for young people, in a historical moment in which much is said about the death of reading. For these reasons, the main potential of the platform from the educational point of view is, in our opinion, that Wattpad brings students closer to the world of reading and writing through a purely informal channel based on peer-to-peer relationships. Literary work material is categorized according to different genres such as classic (romance, action, adventure, horror, fantasy) and the new forms such as Teen Fiction, Chick Lit and
Fanfiction are categorized as the literary works produced by the users.

In addition, Ebrahimi (2016) explained that digital reading allows the students to choose materials based on their proficiency level and interests. It provides literary work as reading material for understanding to have pleasure and independent reading. Digital reading is reading the texts from the technological medium such as the cellphones, tablets, or computers either online or offline. Digital reading like wattpad platform helps reading comprehension of literature because it is fast to access and interesting reading material.

Rebora \& Pianzola (2018) stated wattpad is a very important resource for everybody interested in literature. It is a platform available via web and as a mobile app, on which people can add comments in the margins of books in the public domain, writing their response to what they are reading and engaging in discussions with other users that commented before them. This is the most striking difference concerning other social reading practices since the social aspect of social reading and writing reviews, rating and recommending books. The student can create a free account to start writing on Wattpad platform. The owner of Wattpad platform account will be able to post articles, stories, or poems. Users can also provide comment and vote on each reading. Wattpad platform also can read on the computer, smartphone, or tablet readers. One of the uniqueness of the average writer in the Wattpad is teenagers. Most of these teenagers write a fan fiction story. Fan fiction is a story where the 
characters are the idol of the writer. That is why the Wattpad platform is suitable for students.

The use of prose such as short stories makes the task of reading is easier than the other literary genres. It can be concluded that literary work like short story helps the student focused on the story content, plot and language components (Tevdovska, 2016). The following description is the strategies for teaching literature proposed by Zhen cited in Novianti (2016):

1. Prepare the task of teaching English as literary appreciation and language components in balance.

2. Selecting the best benefit and disbenefit in the use of technology for teaching literature.

3. Giving more attention to students' learning process.

4. Motivating students to different levels of English proficiency.

5. Applying a suitable assessment pattern.

6. Applying various methods in teaching literature.

Teaching English literature needed the appropriate approach that has been popularly used, namely the language model, the cultural model, and the personal growth model. The three models will be briefly discussed as follow:

1. The language model focuses on how language is used in literary texts focusing on grammar, syntactical, and lexical aspects of the literary texts.

2. The cultural model exposes the literary work as resources to learn about the culture and ideology through the plot, the characters, and settings of the texts;
3. The personal growth model focuses on the model that combines the language and cultural models; it's looking at the linguistic elements in the context of the text's culture. In this approach, students are given the freedom to express their aesthetic appreciation of the literary texts and interpret the cultural as well as ideological values contained in the texts.

Based on the exploration above, learning English prose using blended learning with wattpad platforms are expected to be able to maximize the quality of students in understanding the meaning of literary learning. In essence, examining literary works such as prose can be started by choosing literary material that is appropriate to the level of student needs. The use of the wattpad platform makes it easy for students to access prose literature without the limitations of time and place so that the learning process can be more flexible. The approach to study English prose is needed as a reference for critically reading prose literary works. Learning English prose study using the wattpad platform within the framework of blended learning is as follows:

1. Scheduling online reading of selected literary works through the wattpad platform and face-to-face report study in class,

2. The choice of literary genre on the wattpad platform is tailored to the level of student needs

3. Doing the learning process by creating a student account on wattpad and accessing English prose material on wattpad 
4. Provide prose study tasks with the approach of language models, cultural models, and personal growth models

5. Students present the results of the study of prose as a critical reading result in a face-to-face session

6. Students are given the task to write English short stories by referring to the pattern of their previous literary reading material

7. Students are asked to upload their short story written in their account on the wattpad platform

8. Students are asked to read each other's short stories and their colleagues' comments.

9. The lecturer gives feedback on the results of the students' short story writing in each student's wattpad account.

It can be concluded that the wattpad platform and English prose course blending can be a fun and meaningful alternative to literary learning. Students not only read literary works but they are also asked to write their works and present them so that they practice the evaluative and appreciative abilities of work. Utilization of blended learning through the wattpad platform media is one of the practical solutions for students and lecturers to have active interaction both face to face and online.

\section{CONCLUSION}

$\mathrm{L}$ earning literature uses more media books but the development of technology makes it easier for students to more flexibly access literary works such as prose through the wattpad platform. Prose studies that require critical reading skills can in fact be integrated with the wattpad platform and face-to-face sessions in the classroom so learning is more interactive and meaningful. In addition, the wattpad platform can be used to publish literary works by students in the form of prose to further obtain constructive peer to peer feedback. Therefore the blending wattpad platform and English prose course are expected to answer the challenges of the industrial revolution 4.0 by implementing technology-based learning.

\section{REFERENCES}

Alkhaleel, A. (2019). The Advantages of Using Blended Learning in Studying English as a Foreign Language at the University of Tabuk. Modern Journal of Language Teaching Methods (MJLTM), 1-7. https://doi.org/10.26655/mjltm.20 19.2 .5

Bal, M. (2018). Reading and Writing Experiences of Middle School Students in the Digital Age: Wattpad Sample. International Journal of Education and Literacy Studies, 6(2), 89-100. Retrieved from http://www.journals.aiac.org.au/ind ex.php/IJELS/article/view/4439/34 41

Bold, M. R. (2018). The Return of the Social Author: Negotiating Authority and Influence on Wattpad. Convergence: The International Journal of Research into New Media Technologies, 24(2), 117-136. https://doi.org/10.1177/13548565 16654459

Ebrahimi, S. S. (2016). Effect of Digital Reading on Comprehension of English Prose Texts in EFL/ESL Contexts. International Journal of English Language and Literature 
Studies, 5(2), 111-117. Retrieved from

https://ideas.repec.org/a/asi/ijells/ 2016p111-117.html

Ezeokoli, F. O. (2016). Effects of Two Methods of Instruction on Students' Critical Response to Prose Literature Text in English in Some Secondary Schools in Benin City. International Journal of Education and Practice, 4(5), 167-182. https://doi.org/10.18488/journal.6 1/2016.4.5/61.5.167.182

Gill, R. (1995). Mastering English Literature. London: Macmillan International Higher Education.

Jeffrey, L., Milne, J., Suddaby, G., \& Higgins, A. (2014). Blended Learning: How Teachers Balance the Blend of Online and Classroom Components. Journal of Information Technology Education: Research, 13, 121-140. https://doi.org/10.28945/1968

Nassaji, H. (2015). Qualitative and Descriptive Research: Data Type Versus Data Analysis. Language Teaching Research, 19(2), 129-132. https://doi.org/10.1177/13621688 15572747

Novianti, N. (2016). English Literature Teaching: An Indonesian Context. Indonesian Journal of Applied Linguistics, $\quad 6(1), \quad 42$. https://doi.org/10.17509/ijal.v6i1.2 660

Rebora, S., \& Pianzola, F. (2018). A New Research Programme for Reading Research: Analysing Comments in the Margins on Wattpad. DigitCult Scientific Journal on Digital Cultures, $3(2)$, 19-36. https://doi.org/10.4399/97888255 181532

Tevdovska, E. S. (2016). Literature in ELT Setting: Students' Attitudes and Preferences towards Literary Texts. Procedia - Social and Behavioral Sciences, 232, 161-169. https://doi.org/10.1016/j.sbspro.20 16.10.041

Tirocchi, S. (2018). Wattpad. In C. A. Scolari (Ed.), Teen Media and Collaborative Culture (pp. 93-97). Barcelona: Universitat Pompeu Fabra. 